\title{
MANAJEMEN PAJAK DIPANDANG DARI SISI FISKUS
}

\author{
Dewi Kusuma Wardani \\ Program Studi Akuntansi Fakultas Ekonomi \\ Universitas Sarjanawiyata Tamansiswa \\ E-mail: d3wi_kusuma@yahoo.co.id
}

\begin{abstract}
77.2\% in 2011. Non-tax income decreased from 43.5\% in 2000 to $22.8 \%$ in 2011 (Kemenkeu, 2011). It implies that tax has greater portion in government income, i.e. more than $75 \%$ from total income.

Tax-payers think that tax is a burden for them so they try to reduce it with tax management. Tax management can be viewed as a legal thing, and is not an illegal tax evasion. Although it is legal, tax management can reduce tax income and harm government.

The Indonesian tax income realization was still bellow the target, except in 2008 and 2010. The tax income target inaccessibility makes government was in debt to pay the expenses. The government burdened high tax interest. Tax interest rose from $27.1 \%$ in 2005 to $28.5 \%$ in 2011 . On the other hand, subsidy dropped from $50.2 \%$ in 2005 to $46.5 \%$ in 2011. Subsidy cutting caused by the tax interest increasing showed that government could not welfare their people because the income was not addressed only for their people but for others whom Indonesia has debt.

We can conclude that tax management harms government because it reduces government income, increases debt interest, and reduces government capacity to welfare their people. So, government must monitor tax management practices in order to avoid tax income decreasing because of tax management .
\end{abstract}

Keywords: Tax Management, Government Income, Debt Interest, Subsidy

\section{PENDAHULUAN}

Pajak merupakan kontribusi wajib yang harus dibayar oleh wajib pajak kepada negara/pemerintah yang dapat dipaksakan tanpa ada balas jasa (kontraprestasi) yang secara langsung diterima oleh pembayar pajak (UU 18/2007). Dari definisi tersebut maka semua wajib pajak, mau tidak mau dan suka tidak suka, harus menyisihkan sebagian uangnya untuk membayar pajak. Otomatis pajak dianggap sebagai beban oleh masyarakat karena dengan adanya pajak maka kemampuan ekonomisnya berkurang akibat menyisihkan uangnya untuk membayar pajak. Bahkan, sejak lahirpun orang sudah dikenakan pajak ketika ia menggunakan suatu produk tertentu, seperti bayi yang harus diselimuti kain yang sudah dikenakan pajak pertambahan nilai (PPN).

Konsekuensi dari anggapan bahwa pajak merupakan beban bagi masyarakat adalah masyarakat berusaha untuk tidak membayar pajak. Terdapat dua mekanisme untuk mengurangi pajak yang harus dibayar, yaitu dengan cara penghindaran pajak (tax avoidance) dan penyelundupan pajak (tax evasion). Kedua mekanisme tersebut mirip yang mana keduanya merupakan metoda agar kewajiban perpajakan dapat dikurangi, namun perbedaan diantara keduanya pun sangat besar. Penghindaran pajak adalah perbuatan legal yang masih dalam ruang lingkup pemajakan dan tidak melanggar ketentuan perundang-undangan perpajakan. 
Penyelundupan pajak merupakan perbuatan ilegal yang melanggar ketentuan perundangundangan perpajakan (Zain, 2007).

Tipisnya perbedaan antara penghindaran pajak dan penyelundupan pajak membuat wajib pajak harus pandaipandai dalam mengatur strategi perpajakannya. Disinilah muncul istilah manajemen pajak, yaitu proses mengorganisasi usaha wajib pajak atau kelompok wajib pajak sedemikian rupa sehingga utang pajaknya, baik pajak penghasilan maupun pajak-pajak lainnya, berada dalam posisi yang paling minimal sepanjang hal ini dimungkinkan, baik oleh ketentuan perundang-undangan perpajakan maupun secara komersial (Zain, 2007).

Bila dilihat dari definisinya maka manajemen pajak dianggap legal oleh pemerintah dan tidak akan menimbulkan dampak buruk bagi wajib pajak akibat pengurangan dalam pembayaran pajak. Meskipun demikian, dari sisi negara sebagai fiskus, yaitu pihak yang memungut pajak, tentu saja menajemen pajak perlu dicermati lagi dampaknya karena manajemen pajak dapat mengurangi penerimaan pajak yang notabene merupakan penerimaan terbesar negara, yaitu $77,2 \%$ dari total penerimaan negara tahun 2011 (Kemenkeu, 2011).

Artikel ini akan mengulas mengenai bagaimana pandangan fiskus terhadap fenomena manajemen pajak yang sudah umum dilakukan oleh wajib pajak dan merupakan tindakan yang legal. Dengan membaca artikel ini, pemerintah diharapkan dapat mengatur strategi dalam mengelola manajemen pajak yang dilakukan oleh perusahaan. Selain itu, perusahaan juga diharapkan dapat semakin bijak dalam melakukan manajemen pajak sehingga tidak hanya memikirkan kepentingan bisnis semata, namun juga memikirkan bangsa ini secara holistic. Pembahasannya akan dibagi menjadi lima bagian, yaitu pendahuluan, manajemen pajak, pentingnya pajak bagi negara, manajemen pajak dipandang dari sisi fiskus, dan penutup.

\section{MANAJEMEN PAJAK}

Manajemen pajak, yaitu proses mengorganisasi usaha wajib pajak atau kelompok wajib pajak sedemikian rupa sehingga utang pajaknya, baik pajak penghasilan maupun pajak-pajak lainnya, berada dalam posisi yang paling minimal sepanjang hal ini dimungkinkan, baik oleh ketentuan perundang-undangan perpajakan maupun secara komersial (Zain, 2007). Dari definisi tersebut maka manajemen pajak dapat diartikan sebagai penghindaran pajak yang sifatnya legal, dan bukan penyelundupan pajak yang sifatnya ilegal.

Manajemen pajak dilakukan oleh perusahaan dengan didorong oleh beberapa hal, antara lain (Zain, 2007):

1. Menganggap pajak sebagai beban. Pajak dianggap sebagai beban yang memberatkan sehingga perusahaan berusaha untuk mengurangi beban itu sekecil-kecilnya agar daya belinya tidak berkurang.

2. Adanya ketentuan Undang-undang perpajakan yang membuat celah sehingga manajemen pajak dapat dilakukan, seperti: (a) sistem self assessment dan (2) ketentuan pajak penghasilan mengenai biaya yang dapat dikurangkan dan tidak dapat dikurangkan.

Di lain pihak, Wajib pajak melakukan pelanggaran pepajakan didorong oleh beberapa faktor, seperti (Suandy, 2001):

1. Tax required to pay (besarnya pajak yang harus dibayar). Semakin besar pajak yang harus dibayar maka semakin besar pula kecenderungan wajib pajak untuk melakukan pelanggaran

2. Cost to bribe (biaya untuk menyogok fiskus). Semakin kecil biaya untuk menyogok aparat pajak maka semakin besar kecenderungan wajib pajak untuk melakukan pelanggaran

3. Probability to detection (kemungkinan terdeteksi). Semakin kecil kemungkinan pelanggaran pajak dapat terdeteksi maka semakin tinggi 
kecenderungan wajib pajak untuk melakukan pelanggaran

4. Size to penalty (sanksi). Semakin kecil sanksi yang dikenakan terhadap pelanggaran maka semakin tinggi kecenderungan wajib pajak untuk melakukan pelanggaran

Manajemen pajak dapat dilakukan dengan melaksanakan tindakan penstrukturan yang terkait dengan konsekuensi perpajakan. Beberapa langkah yang harus diambil dalam melakukan manajemen pajak, antara lain (Zain, 2007):

1. Menetapkan sasaran atau tujuan manajemen pajak, yaitu untuk mengefisienkan pajak tanpa melanggar ketentuan perundang-undangan serta tetap melaksanakan segala ketentuan administrative secara baik dan efektif.

2. Mengidentifikasi sutuasi saat ini serta hal-hal yang dapat mendukung dan menghambat tujuan manajemen pajak, seperti identifikasi faktorlingkungan jangka panjang, memahami etika kebijakan perusahaan serta manajemen pajak

\section{PENTINGNYA PAJAK BAGI NEGARA}

Negara memiliki tugas untuk memelihara ketenangan dan ketertiban serta melaksanakan pertahanan dan keamanan, melindungi hak dan harta benda setiap warganya terhadap gangguan anggota masyarakat lainnya, dan menerima pendelegasian yang diberikan oleh rakyat melalui wakil-wakilnya. Pelaksanaan tugas tersebut membutuhkan biaya yang tidak sedikit., yang jumlahnya tergantung dari kegiatan yang akan dilakukan untuk melaksanakan ketiga tugas pemerintah tersebut. Untuk membiayai pengeluaran atau belanja, pemerintah harus memiliki penerimaan Negara (Siahaan, 2010). Rencana biaya dan penerimaan pemerintah Indonesia disebut dengan Anggaran Pendapatan dan Belanja Negara (APBN). Berikut komposisi pendapatan Negara tahun 2000-2011.

Gambar 1

Komposisi Pendapatan Negara

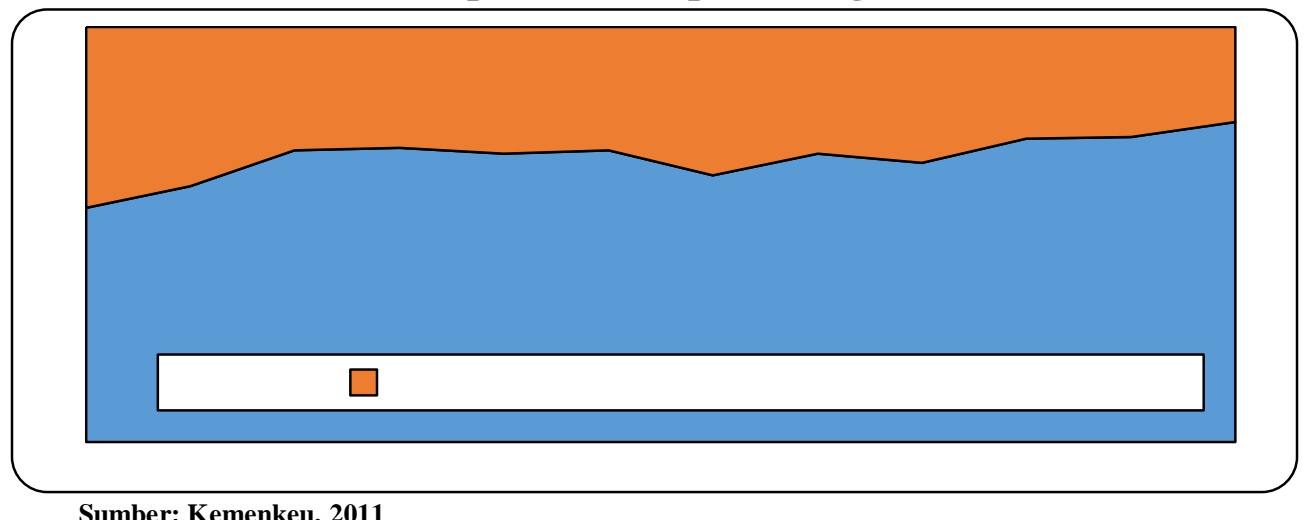

Dalam total pendapatan negara, kontribusi perpajakan meningkat dari 56,5\% di tahun 2000 menjadi 77,2\% di tahun 2011 . Penerimaan negara bukan pajak menurun dari 43,5\% di tahun 2000 menjadi 22,8\% di tahun 2011 (Kemenkeu, 2011). Dari sini dapat kita simpulkan bahwa pajak mengambil porsi yang paling besar dalam pendapatan Negara, yakni lebih dari $75 \%$ total pendapatan Negara. Dapat dikatakan bahwa pajak menjadi penting dalam kelangsungan hidup Republik Indonesia. Seandainya tidak ada pajak yang diperoleh maka Negara ini akan kolaps.

Penerimaan perpajakan berasal dari tiga komponen, yaitu pajak non migas, kepabeanan dan cukai, serta PPH Migas. Beriku komposisi penerimaan perpajakan. 
Gambar 2

Komposisi Penerimaan Perpajakan

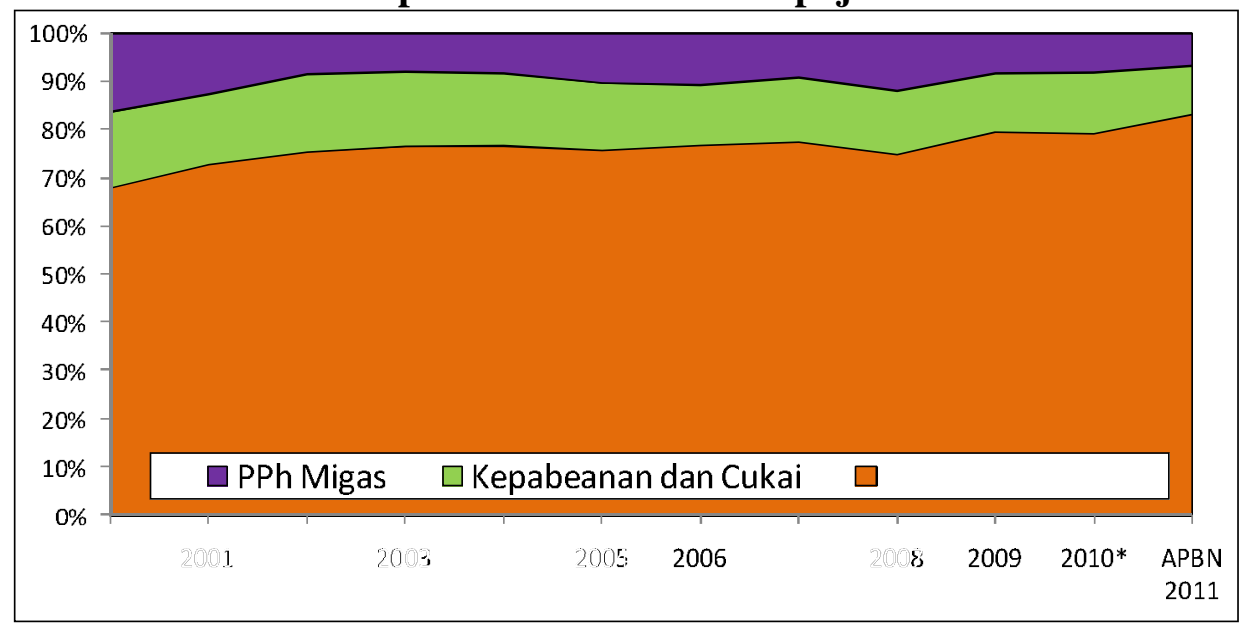

Sumber: Kemenkeu, 2011

Dalam total penerimaan perpajakan, kontribusi pajak non migas meningkat dari $68,1 \%$ di tahun 2000 menjadi $83,4 \%$ di tahun 2011, kepabeanan dan cukai menurun dari $15,8 \%$ di tahun 2000 menjadi $10,1 \%$ di tahun 2011, dan pajak penghasilan ( $\mathrm{PPh}$ ) migas menurun dari $16,1 \%$ di tahun 2000 menjadi $6,5 \%$ di tahun 2011. Dapat disimpulkan bahwa pajak non migas, yang berasal dari PPh, PPn dan PPnBM, PBB, serta bea materai, menjadi sumber terbesar penerimaan Negara dari pajak.

\section{Gambar 3}

\section{Penerimaan Perpajakan}

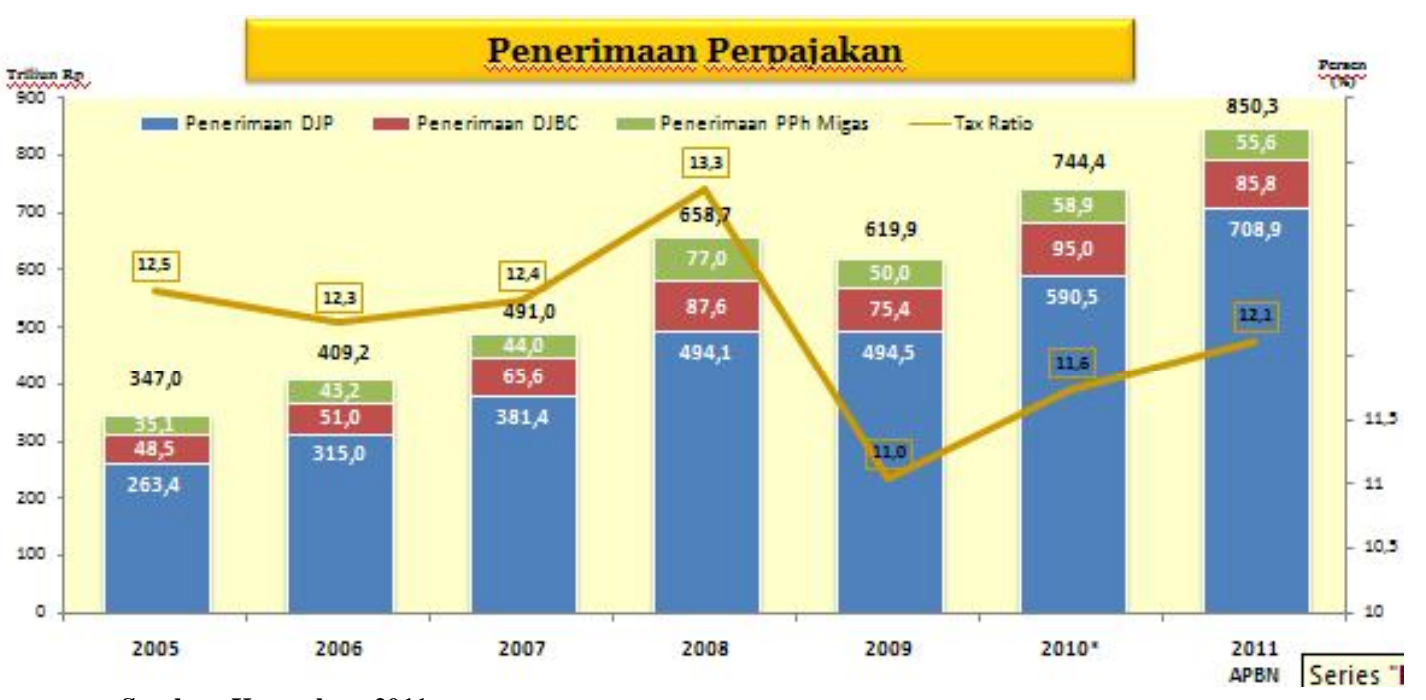

Sumber: Kemenkeu, 2011

Penerimaan perpajakan meningkat lebih dari dua kali lipat pada periode 20052011. Penerimaan perpajakan meningkat rata-rata $16,1 \%$, yang mana tahun 2005 hanya Rp 347 triliun menjadi $\mathrm{Rp} 850,3$ triliun di tahun 2011. Penerimaan Perpajakan dominan didukung dari sumber Pajak
Nonmigas (rata-rata 77,3\%), sedangkan Kepabeanan dan Cukai (13,5\%), dan $\mathrm{PPh}$ Migas $(9,1 \%)$. Tax ratio pada kisaran $11 \%$ $12,5 \%$, kecuali tahun 2008 mencapai 13,3\% oleh dampak tingginya kenaikan harga minyak mentah dan komoditi primer (Kemenkeu, 2011). 


\section{Gambar 4}

Perbandingan Anggaran dan Realisasi Penerimaan Perpajakan

\begin{tabular}{|c|c|c|c|c|c|c|c|c|c|c|c|c|c|c|c|c|c|c|c|}
\hline \multirow{2}{*}{ Vraian } & \multicolumn{3}{|c|}{2005} & \multicolumn{3}{|c|}{2006} & \multicolumn{3}{|c|}{2007} & \multicolumn{3}{|c|}{2008} & \multicolumn{3}{|c|}{2008} & \multicolumn{3}{|c|}{2010} & 2011 \\
\hline & APBNF & Real & $\%$ & APBA & Real & $\%$ & APBN-P & Real & $\%$ & APBN.P & Real & $\%$ & APEN-P & Real & $\%$ & APBN-P & Real" & $\%$ & APBN \\
\hline Penerimaan Perpajakan & & 34,0 & 98,6 & & 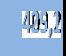 & 96,3 & & 491, & 99,8 & 609,2 & 658,7 & 108,1 & & 648 & 95,1 & & 746 & 100,1 & 850,3 \\
\hline Penerimaan D.P & & 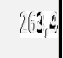 & 99,4 & & is & 94,6 & 395,2 & 381,4 & 96,5 & & $4:$ & 1027 & & an: & 93,6 & & 5.914 & 97,4 & 708,9 \\
\hline Penerimaan D.BCC & & 65 & & $3, ?$ & 51,0 & 95,6 & 59,5 & 65,6 & 110,3 & 74,7 & 87,6 & 117,3 & 74,6 & 75,4 & 101,1 & & ii & 116,1 & 85,8 \\
\hline PPh Migas & 37,2 & 35,1 & & $y i$ & 43,2 & 111,6 & 37,3 & 4,0 & 118,1 & & $\because:$ & 143,6 & 49,0 & 50,0 & 102,0 & & 16 & 106,3 & 55,6 \\
\hline
\end{tabular}

Sumber: Kemenkeu, 2011

Jika dilihat dari tabel di atas maka dapat kita simpulkan bahwa realisasi penerimaan pajak masih di bawah target, kecuali tahun 2008 dan 2010, padahal pemerintah sudah membuat kebijakan fiscal yang diharapkan dapat mempengaruhi optimalisasi penerimaan pajak. Beberapa kebijakan atau insentif fiskal yang mempengaruhi optimalisasi penerimaan pajak, antara lain (www.pajak.go.id):

1. 2006 : Peningkatan PTKP dari Rp12 juta menjadi Rp13,2 juta

2. 2007 : Penyelesaian seluruh kewajiban restitusi yang belum dibayarkan pada tahun-tahun sebelumnya

3. 2008 : Sunset policy yang memberikan penghapusan denda/bunga

4. 2009 : Amandemen UU PPh berupa penurunan tarif $\mathrm{PPh}$ (OP 5\% \& Badan 2\%) dan peningkatan PTKP dari Rp13,2 juta menjadi Rp15,8 juta

5. 2010 : Amandemen UU PPN yang memberikan pembebasan untuk beberapa komoditi tertentu dan lanjutan pelaksanaan amandemen UU PPh berupa penurunan tarif $\mathrm{PPh}$ badan (3\%)

\section{MANAJEMEN PAJAK DIPANDANG DARI PIHAK FISKUS}

Dalam kaitannya dengan manajemen pajak, fiskus mengalami dilemma. Di satu sisi, manajemen pajak merupakan suatu kegiatan yang legal sehingga pemerintah tidak boleh memperkarakan kegiatan itu sepanjang tindakan yang dilakukan wajib pajak tidak menyalahi peraturan perpajakan. Di sisi lain, manajemen pajak dapat menimbulkan kerugian pajak (tax losses) yang terjadi akibat adanya selisih antara potensi pajak dan realisasi penerimaan pajak (Zain, 2007). Oleh sebab itu, perlu dicermati arti pentingnya kerugian pajak tersebut pada masyarakat Indonesia secara keseluruhan.

Di awal artikel ini telah dibahas bahwa penerimaan pajak digunakan sebagai salah satu sumber penerimaan Negara guna membiayai belanja Negara. Apabila penerimaan dari pajak dan penerimaan non pajak kurang maka pemerintah harus menutup biaya tersebut dengan melakukan utang, baik utang dalam negeri dan utang luar negeri. Konsekuensi dari utang adalah bunga utang yang harus dibayar setiap tahun 


\section{JURNAL AKUNT ANSI. VOL.1 NO.1 JUNI 2013}

\section{Gambar 5}

Anggaran Belanja Negara

\begin{tabular}{|c|c|c|c|c|c|c|c|c|c|c|c|c|c|c|c|}
\hline \multirow{2}{*}{ Belanja Pemerintah Pusat } & \multicolumn{2}{|c|}{2005} & \multicolumn{2}{|c|}{2006} & \multicolumn{2}{|c|}{2007} & \multicolumn{2}{|c|}{2008} & \multicolumn{2}{|c|}{2009} & \multicolumn{2}{|c|}{2010} & \multicolumn{2}{|c|}{2011} & \multirow{2}{*}{$\begin{array}{c}\text { Pertumbuhan } \\
\text { Rata-rata }\end{array}$} \\
\hline & Real & YoY (\%) & Real & YoY (\%) & Real & YoY $(\%)$ & Real & YoY (\%) & Real & YoY (\%) & Real & $\operatorname{YoY}(\%)$ & APBN & YoY (\%) & \\
\hline I. Betanja Pemeinteh Pusat & 3612 & $21.4 \%$ & 440.0 & $21.8 \times$ & 504.6 & $14.7 \%$ & 693.4 & $37.4 \%$ & 628.8 & $-9.3 \%$ & 711.8 & $13.2 \%$ & 836.6 & $17.5 \%$ & $15.0 \%$ \\
\hline Belanja K/L & 120.8 & $18.2 \%$ & 189.4 & $56.7 \%$ & 225.0 & $18.8 \%$ & 259.7 & $15.4 \%$ & 307.0 & $18.2 \%$ & 325.3 & $6.0 \%$ & 432.8 & $33.0 \%$ & $23.7 \%$ \\
\hline 1. Betanja Pegawai & 54.3 & $2.9 \%$ & 73.3 & $35.0 \times$ & 90.4 & 23.44 & 112.8 & $24.8 \%$ & 127.7 & $13.2 \%$ & 147.8 & $15.8 \%$ & 180.8 & $22.3 \%$ & $22.2 \%$ \\
\hline 2. Betanja Barang & 292 & $88.0 \%$ & 472 & $61.7 \times$ & 54.5 & $15.5 \%$ & 56.0 & $27 \%$ & 80.7 & $44.1 \%$ & 96.0 & $19.0 \%$ & 137.8 & $43.6 \%$ & $29.5 \%$ \\
\hline 3. Bełanja Kbda & 32.9 & $-46.5 \%$ & 55.0 & $67.1 \%$ & 64.3 & $17.0 \%$ & 72.8 & 13.2\% & 75.9 & $4.3 \%$ & 7.0 & $1.4 \%$ & 135.9 & $76.5 \%$ & $26.7 \%$ \\
\hline 4. Penbajeran Bunga Uleang & 652 & $43 \times$ & 79.1 & $21.3 \times$ & 79.8 & $0.9 \%$ & 88.4 & $10.8 \%$ & 93.8 & $6.1 \%$ & 88.3 & $-5.8 \%$ & 115.2 & $30.4 \%$ & $10.0 \%$ \\
\hline 5. Subsid & 120.8 & $31.9 \%$ & 1074 & $-11.0 \%$ & 150.2 & $39.8 \%$ & 275.3 & $83.3 \%$ & 133.1 & $-49.8 \%$ & 24.1 & $55.1 \%$ & 187.6 & $-12.4 \%$ & $7.6 \%$ \\
\hline 6. Betanja Hbah & 0.0 & $0.0 \%$ & 0.0 & 0.04 & 0.0 & $0.0 \%$ & 0.0 & $0.0 \%$ & 0.0 & $0.0 \%$ & 0.1 & $0.0 \times$ & 0.8 & $0.0 \%$ & $0.0 \%$ \\
\hline 7. Bartuen Sosial & 24.9 & $0.0 \%$ & 40.7 & $63.5 \times$ & 49.8 & $222 \%$ & 57.7 & $16.0 \%$ & 73.8 & $27.8 \%$ & 68.4 & $-7.3 x$ & 63.2 & $-7.6 \%$ & $16.8 \%$ \\
\hline 8. Betanja Laintain & 34.0 & $1473 \%$ & 37.4 & $102 x$ & 15.6 & -58.34 & 30.3 & $94.1 \%$ & 38.9 & $28.4 \%$ & 20.1 & $-48.3 x$ & 15.3 & $-24.1 \%$ & $-12.5 \%$ \\
\hline
\end{tabular}

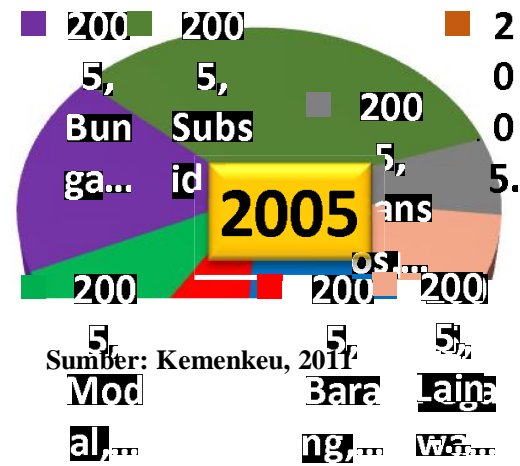

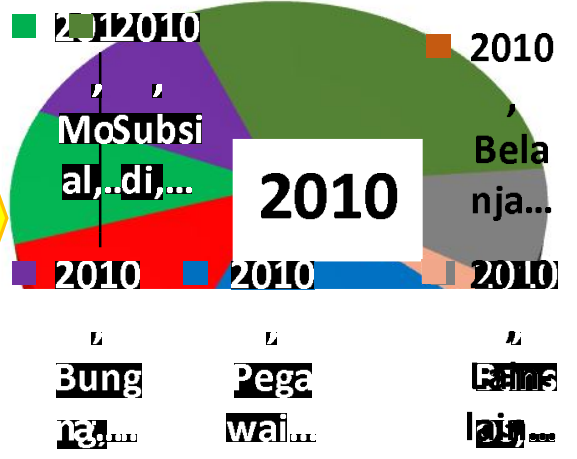

Bahkan bunga utang lebih besar prosentasenya daripada pengeluaran untuk maka dapat kita simpulkan bahwa prosentasenya daripada
pemerintah harus mengalokasikan lebih dari bantuan sosial (bansos). $10 \%$ penerimaannya pada bunga utang.

\section{Gambar 6}

Belanja Non K/L Meningkat Rata-rata 11,6\% dengan Proporsi Belanja Subsidi Menurun sedangkan Pembayaran Bunga Utang Meningkat

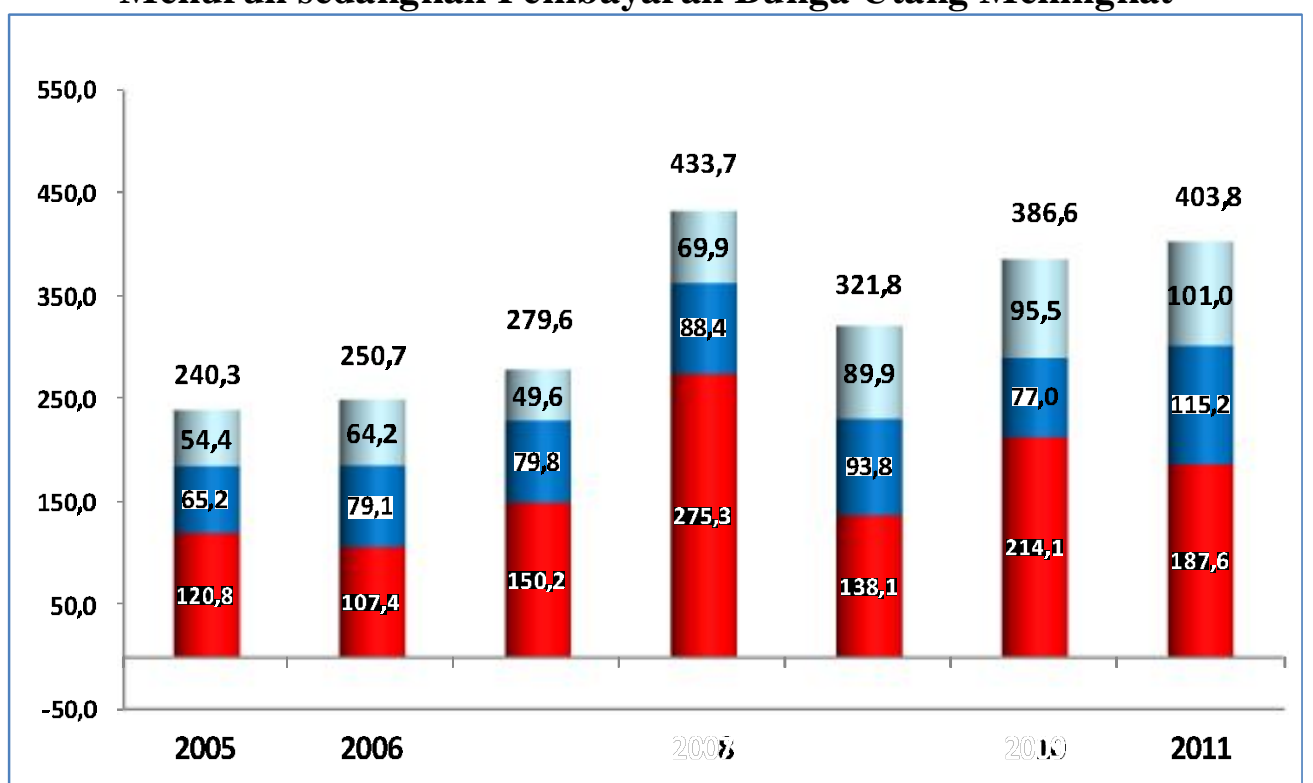




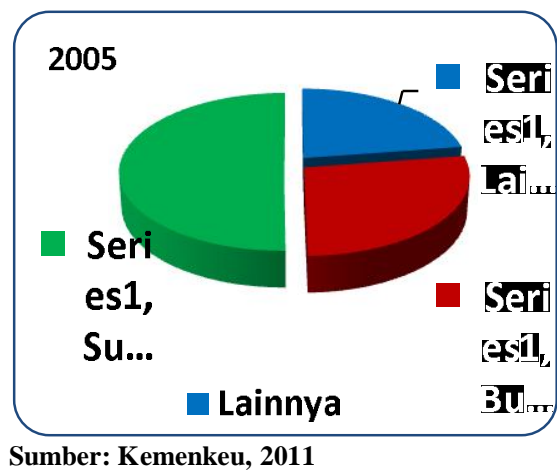

Dari gambar 6 dapat kita lihat bahwa Belanja non $\mathrm{K} / \mathrm{L}$ meningkat rata-rata $11,6 \%$, berasal dari peningkatan subsidi $(17,5 \%)$ dan bunga utang $(11,8 \%)$. Proporsi subsidi cenderung menurun, dimana sebesar $50,2 \%$

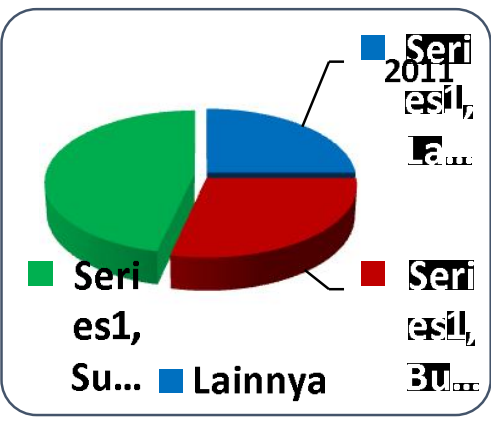

di tahun 2005 menjadi $46,5 \%$ pada tahun 2011, sedangkan proporsi bunga utang meningkat, yaitu $27,1 \%$ di tahun 2005 menjadi 28,5\% di tahun 2011 .

Gambar 7

Pembiayaan Utang 2009-2011

\begin{tabular}{|l|c|c|c|}
\hline \multirow{2}{*}{ Uraian } & \multicolumn{2}{|c|}{ Realisasi } & APBN \\
\cline { 2 - 3 } & $\mathbf{2 0 0 9}$ & $\mathbf{2 0 1 0}$ & $\mathbf{2 0 1 1}$ \\
\hline Bunga Utang & $\mathbf{9 3 , 8}$ & $\mathbf{8 8 , 4}$ & $\mathbf{1 1 5 , 2}$ \\
Pembiayaan Utang & $\mathbf{8 3 , 9}$ & $\mathbf{8 6 , 6}$ & $\mathbf{1 2 7 , 0}$ \\
\hline SBN Neto & 99,5 & 91,2 & 126,7 \\
Penerbitan & 148,5 & 167,6 & 215,0 \\
Jatuh Tempo dan Buy Back & $(49,1)$ & $(76,5)$ & $(88,3)$ \\
Pinjaman Luar Negeri Neto & $(15,5)$ & $(5,0)$ & $(0,6)$ \\
Penarikan Pinjaman & 58,7 & 52,0 & 58,9 \\
Pinjaman Program & 28,9 & 28,8 & 19,8 \\
Pinjaman Proyek & 29,7 & 23,2 & 39,1 \\
Pemerintah Pusat & 23,5 & 16,8 & 27,4 \\
Penerimaan & & & \\
Pinjaman & 6,2 & 6,4 & 11,7 \\
Penerusan Pinjaman & $(6,2)$ & $(6,4)$ & $(11,7)$ \\
Pembayaran Cicilan Pokok PLN & $(68,0)$ & $50,6)$ & $(47,8)$ \\
Pinjaman Dalam Negeri & - & 0,4 & 1,0 \\
\hline \multicolumn{2}{|c|}{}
\end{tabular}

Sumber: Kemenkeu, 2011

Tidak pernah kita bayangkan apabila pemotongan subsidi oleh pemerintah diakibatkan oleh peningkatan prosentase pembayaran bunga utang. Hal ini menyebabkan tugas pemerintah untuk menyejahterakan masyarakat tidak tercapai karena penerimaan Negara bukan ditujukan untuk subsidi, tetapi malahan diberikan kepada pihak-pihak lain, baik dari dalam maupun luar negeri, yang memiliki piutang pada Negara. Bahkan jika kita lihat dari gambar 7 dapat disimpulkan bahwa bunga utang lebih banyak disetorkan pada luar negeri.

\section{PENUTUP}

Pajak merupakan pendapatan utama Negara. Dalam total pendapatan negara, 
kontribusi perpajakan meningkat dari $56,5 \%$ di tahun 2000 menjadi 77,2\% di tahun 2011 . Penerimaan negara bukan pajak menurun dari 43,5\% di tahun 2000 menjadi 22,8\% di tahun 2011 (Kemenkeu, 2011). Hal tersebut menunjukan bahwa pajak mengambil porsi yang paling besar dalam pendapatan Negara, yakni lebih dari $75 \%$ total pendapatan Negara.

Dari sisi wajib pajak, pajak dianggap sebagai beban bagi masyarakat. Hal ini menyebabkan masyarakat berusaha mengurangi beban pajak melalui manajemen pajak. Manajemen pajak dapat diartikan sebagai penghindaran pajak yang sifatnya legal, dan bukan penyelundupan pajak yang sifatnya ilegal. Meskipun manajemen laba dianggap legal, namun tetap dapat mengurangi pendapatan pajak sehingga merugikan fiskus.

Realisasi penerimaan pajak masih di bawah target, kecuali tahun 2008 dan 2010, padahal pemerintah sudah membuat kebijakan fiscal yang diharapkan dapat mempengaruhi optimalisasi penerimaan pajak. Tidak tercapainya target penerimaan pajak menyebabkan pemerintah harus berhutang untuk membiayai pengeluaran Negara. Hutang ini membuat pemerintah dibebani oleh bunga pajak yang sangat tinggi. Proporsi bunga utang meningkat dari $27,1 \%$ di tahun 2005 menjadi $28,5 \%$ di tahun 2011, sedangkan proporsi subsidi cenderung menurun sebesar $50,2 \%$ di tahun 2005 menjadi $46,5 \%$ pada tahun 2011. Pemotongan subsidi oleh pemerintah yang diakibatkan oleh meningkatnya prosentase pembayaran bunga utang menunjukkan bahwa pemerintah tidak mampu menyejahterakan masyarakat karena penerimaan Negara bukan ditujukan untuk subsidi masyarakat, tetapi malahan diberikan kepada pihak-pihak lain, baik dari dalam maupun luar negeri, yang memiliki piutang pada Negara.

Dari sini dapat disimpulkan bahwa manajemen pajak dapat merugikan fiskus karena menurunkan pendapatan, meningkatkan beban bunga hutang, dan menurunkan kemampuan Negara untuk menyejahterakan masyarakat. Oleh sebab itu, pemerintah harus mengawasi proses manajemen pajak ini agar penerimaan pajak tidak semakin berkurang akibat manajemen pajak yang dilakukan oleh wajib pajak.

\section{DAFTAR PUSTAKA}

Kemenkeu.2011.Materi

Lokakarya

Kebijakan Keuangan Negara bagi kalangan Dosen Fakultas Ekonomi Perguruan Tinggi Provinsi D.I.Yogyakarta.Jakarta: Kementerian Keuangan RI

Siahaan, Marihot Pahala.2010.Hukum Pajak Elementer: Konsep Dasar Perpajakan di Indonesia. Yogyakarta: Graha Ilmu

Suandy.2001.Manajemen Pajak.Jakarta: Salemba Empat

www.pajak.go.id, diakses tanggal 7 Agustus 2011

Zain, Mohammad.2007.Manajemen Perpajakan.Jakarta: Salemba Empat 